\title{
PENERAPAN METODE E-COMMERCE UNTUK MENINGKATKAN PENJUALAN BARANG PADA TOKO NAJWA JEANS
}

\author{
Zakki Mubarak ${ }^{1)}$, Ady Widjaja ${ }^{2}$ \\ ${ }^{1}$ Sistem Informasi, Fakultas Teknologi Informasi, Universitas Budi Luhur \\ ${ }^{1,2} \mathrm{Jl}$. Raya Ciledug, Petukangan Utara, Kebayoran Lama, Jakarta Selatan 12260 \\ E-mail : zakkimubarak03@gmail.com ${ }^{1)}$, ady.widjajaja@budiluhur.ac.id ${ }^{2)}$
}

\begin{abstract}
Abstrak
Najwa Jeans adalah perusahaan yang bergerak di bidang bisnis yang menjual berbagai macam celana jeans. Proses bisnis pada bagian penjualan barang di toko najwa jeans masih bersifat konvensional dimana pelanggan harus datang langsung ke toko untuk membeli barang., persoalan penjualan secara langsung tersebut membuat lingkup penjualan menjadi terbatas. Dari permasalahan itu dibuatkan sebuah website e-commerce. Langkah pengumpulan data pun dilakukan dengan cara observasi, wawancara, Analisa dokumen, dan studi pustaka. Lalu dilanjutkan dengan pembuatan Bussines Model Canvas (BMC) yang dapat membantu mempercepat proses analisis kekuatan dan kekurangan bisnis yang dijalani. Untuk analisis sistem menggunakan metode UML (Unified Modeling Language) yaitu activity diagram, use case diagram, class diagram, dan system sequence diagram. Pada penelitian ini juga diterapkan metode SEO (Search Engine Optimization) untuk memasarkan produk di google agar menjadi nomor satu di halaman google. Focus penelitian ini menyampaikan informasi produk dan penjualan produk secara online kepada pelanggan. Manfaat yang didapat adalah pelanggan tidak perlu lagi untuk datang langsung ke toko sehingga proses transaksi menjadi efisien dan ruang lingkup yang menjadi luas.
\end{abstract}

Kata kunci: E-Commerce, Bussiness Model Canvas, Unified Modeling Language, Search Engine Optimization.

\section{PENDAHULUAN}

Perkembangan Teknologi Informasi yang berkembang dengan sangat cepat seiring dengan kebutuhan manusia yang terus bertambah, membuat teknologi memiliki peran yang sangat penting akan kehidupan manusia. Untuk mengikuti perkembangan zaman, manusia saat ini dituntut untuk mengikuti perkembangan teknologi yang akan terus berkembang dari masa ke masa, jika manusia tidak mengikuti perkembangan teknologi maka dapat dipastikan akan menjadi masyarakat terbelakang. Dengan semakin berkembangnya teknologi mendorong berkembangnya E-Commerce.

E-Commerce (Electronic Commerce) adalah pembelian, penjualan, dan pemasaran barang yang dilakukan melalui sistem elektronik, seperi melalui internet, televisi, dan jaringan komputer. ECommerce sendiri juga menguntungkan banyak pihak, seperti pihak konsumen, produsen, dan penjual. Dengan media ini memudahkan transaksi yang dapat dilakukan secara efektif dan efesien.

Tujuan dari penelitian ini yaitu mempermudah penyajian informasi yang dibutuhkan agar bisa mengefektifkan transaksi jual-beli yang dilakukan, dan mempermudah pembuatan laporan penjualan dan stok pada toko najwa jeans.

Masalah yang dihadapi dalam penjualan barang di toko najwa jeans yaitu promosi yang tidak memiliki jangkauan yang luas, konsumen yang masih harus datang langsung ke toko untuk proses transaksi jual-beli, dan laporan penjualan yang masih tercecer yang mengakibatkan data mudah hilang dan rusak.

Metode Penelitian yang dilakukan yaitu dengan metode pengumpulan data dengan metode Observasi, Wawancara, Analisa Dokumen, dan Studi Kepustakaan. Metode Penelitian selanjutnya yaitu dengan menggunakan Metode Analisa dengan menggunakan metode Analisa Proses Bisnis, Analisa Masalah, Analisa Perancangan Sistem, dan Analisa dengan Bussiness Model Canvas.

\section{PENELITIAN SEBELUMNYA}

a. Penelitian yang dilakukan oleh [1] melakukan penelitian Sistem Penjualan Berbasis Web (E-Commerce) Pada Tata Distro Kabupaten Pacitan. Jurnal Bianglala Informatika Vol 3 No 2 September 2015. Tujuan dari penelitian ini yaitu Dengan adanya pembuatan web pemasaran pada Tata Distro, maka pihak toko dapat terbantu memasarkan produk fashion secara online dan konsumen akan mudah memesan produk-produk fashion terbaru.

b. Penelitian yang dilakukan oleh [2] melakukan penelitian Sistem Informasi Penjualan Online (E-Commerce) menggunakan CMS Wordpress Pada Toko Soraya Shop Dengan Menerapkan Metode RAD. SHap-SITI 2017. Tujuan dari penelitian ini yaitu menghasilkan sebuah 
sistem informasi penjualan online yang menyediakan berbagai jenis pakaian wanita yang di jual pada Toko Soraya Shop, Menyajikan tampilan penjualan online yang menarik dan mempermudah customer dalam melakukan pembelanjaan online di Toko Soraya Shop, dengan CMS WordPress, dan Mempermudah admin dalam mengelolah data penjualan yang akan di-input-kan dalam sistem.

c. Penelitian yang dilakukan oleh [3] melakukan penelitian Sistem Informasi Penjualan Produk Berbasis Web Pada Chanel Distro Pringsewu. Jurnal TAM (Technology Acceptance Model) Volume 4 Juli 2015. Tujuan dari penelitian ini yaitu dapat membantu dalam menawarkan dan memperluas area promosi, pelanggan dapat meminimalisir waktu karena pelanggan dapat berbelanja dimanapun dan kapanpun, Dengan aplikasi website ini dapat menampilkan informasi barang lengkap dengan gambar, harga, view detail, dan deskripsi produk yang akan dipesan, dan Dari aplikasi yang telah dibuat, pemilik toko dapat melihat laporan transaksi penjualan setiap bulannya.

\section{METODE PENELITIAN}

Pada gambar 1 merupakan metode penelitian yang dilakukan yang dimulai dari start, lalu membuat kerangka pemikiran, melakukan pengumpulan data dengan metode observasi lalu wawancara kemudian Analisa dokumen, dan studi kepustakaan. Proses selanjutnya yaitu Analisa proses bisnis, kemudian melakukan Analisa masalah, lalu Analisa perancangan system, dan terakhir membuat Bussiness Model Canvas.

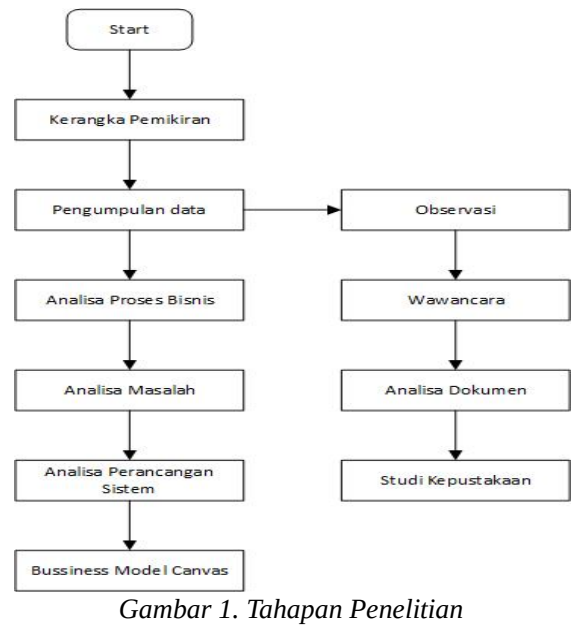

Gambar 1 merupakan langkah-langkah proses tahapan penelitian.

\subsection{Pengumpulan Data}

Pengumpulan data yang dilakukan pada toko najwa jeans yaitu dengan menggunakan metode Observasi, Wawancara, Analisa Dokumen, dan Studi Kepustakaan.

\subsection{Preprocessing}

Pada proses ini menggunakan UML (Unified Modeling Languange). UML yang digunakan yaitu Activity Diagram yang digunakan untuk mengetahui proses bisnis yang berjalan pada toko najwa jeans. Use Case yang digunakan untuk mengetahui aktor yang terlibat dalam proses bisnis yang berjalan. Class Diagram untuk mengetahui database. Dan terakhir System Sequence Diagram untuk mengetahui sistem yang berjalan pada penelitian ini.

\subsection{Metode Yang Digunakan}

Metode yang digunakan pertama yaitu membuat kerangka pemikiran untuk menyelesaikan penelitian ini. Untuk menganalisa masalah pada toko Najwa Jeans ini, maka diperlukan pendekatan masalah dengan metode pengumpulan data yaitu dengan observasi, dan wawancara sehingga dapat mengetahui data dan menganalisa proses bisnis yang ada menggunakan Activity Diagram, Use Case Diagram, Class Diagram, dan System Sequence Diagram. Kemudian Metode Bussiness Model Canvas untuk menggambarkan bagaimana organisasi menciptakan manfaat dan mendapatkan manfaat bagi dan dari pelanggannya.

\section{HASIL DAN PEMBAHASAN}

\subsection{Bussiness Model Canvas}

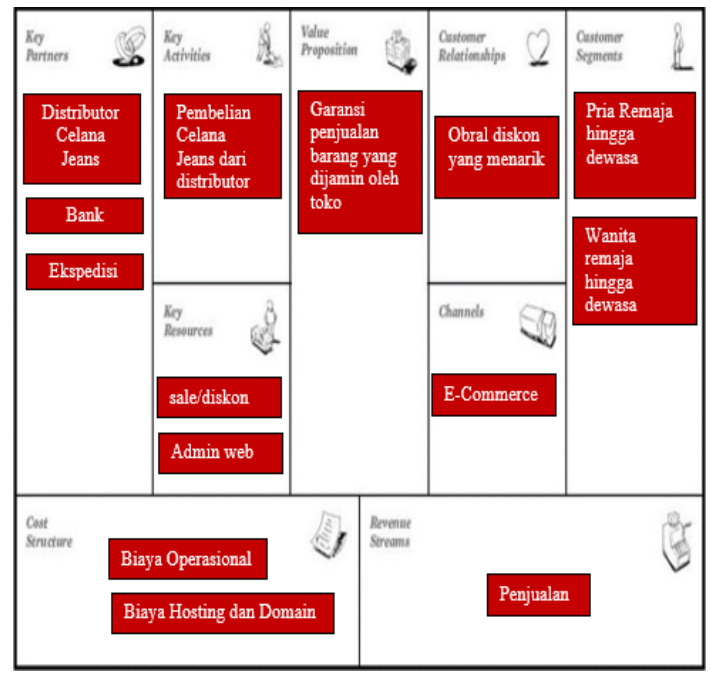

Gambar 2. Bussiness Model Canvas 
Key Partners Difokuskan pada mitra usaha perusahaan dan peranannya dalam memberikan sumber daya yang dibutuhkan. Dalam menjalankan bisnisnya Najwa Jeans memiliki kerja sama dengan distributor celana jeans, Ekspedisi dan Bank.

Key Activities difokuskan pada gambaran aktivitas perusahaan dan efektifitas dari aktivitas yang dijalankan. Aktivitas utama yang dilakukan di toko najwa jeans yaitu melakukan pembelian barang kepada pihak distributor.

Key Resource disini menggambarkan jaringan pemasok dan mitra yang membuat model bisnis dapat berjalan. Kunci penting untuk meningkatkan bisnis di toko najwa jeans yaitu sale/diskon dan admin web.

Value propositions difokuskan pada mengidentifikasi kebutuhan pelanggan perusahaan, mengetahui kemampuan perusahaan menerapkan nilai dalam memenuhi kebutuhan pelanggan, kemudian bagaimana perusahaan mampu meningkatkan kinerja dan menciptakan brand images yang baik bagi perusahaan serta dalam hal penetapan harga. Value propositions yang dimiliki toko najwa jeans dibandingkan toko yang lain, yaitu Garansi penjualan barang yang dijamin oleh toko.

Customer relationship disini adalah berfokus pada pola hubungan perusahaan dengan pelanggan, cara perusahaan dalam menciptakan hubungan yang baik dengan pelanggannya. Dalam melakukan penawaran toko najwa jeans menawarkan diskon yang menarik kepada pelanggan agar meningkatkan penjualan produk.

Customer Segment disini adalah berfokus untuk mengidentifikasi kelompok konsumen yang dituju oleh perusahaan sebagai target penjualan. Dalam meningkatkan penjualan toko najwa jeans memiliki target pasar yaitu pria remaja hingga dewasa dan wanita remaja hingga dewasa.

Channel disni adalah difokuskan pada metode dan jenis proses untuk menjangkau pelanggan. Toko Najwa Jeans dalam memasarkan produknya kepada customer menggunakan e-commerce.

Cost Structure Dalam penelitian ini cost structure yang diteliti difokuskan pada jenis-jenis dan sumber biaya perusahaan. Dalam melakukan bisnis toko najwa jeans mengeluarkan biaya yaitu biaya operasional dan hosting \& domain.

Revenue streams yang diteliti difokuskan pada sumber pendapatan perusahaan yang juga dilihat dari jenis pendapatannya, cara pembayaran oleh pelanggan dan perbandingan pendapatan yang diterima dengan manfaat yang diberikan perusahaan bagi pelanggan. Merupakan pendapatan yang didapat oleh toko najwa jeans, pendapatan itu dihasilkan dari penjualan.

\subsection{Proses Bisnis Usulan}

a. Activity Diagram Pendaftaran Pelanggan

Pelanggan mengunjungi website najwajeanstore.com, kemudian pilih menu account lalu mengisi form register dengan mengisi data diri setelah selesai pilih klik register dan data akan otomatis tersimpan kemudian pelanggan menerima email notifikasi register. Berikut merupakan gambar yang menjelaskan Activity proses pendaftaran pelanggan.

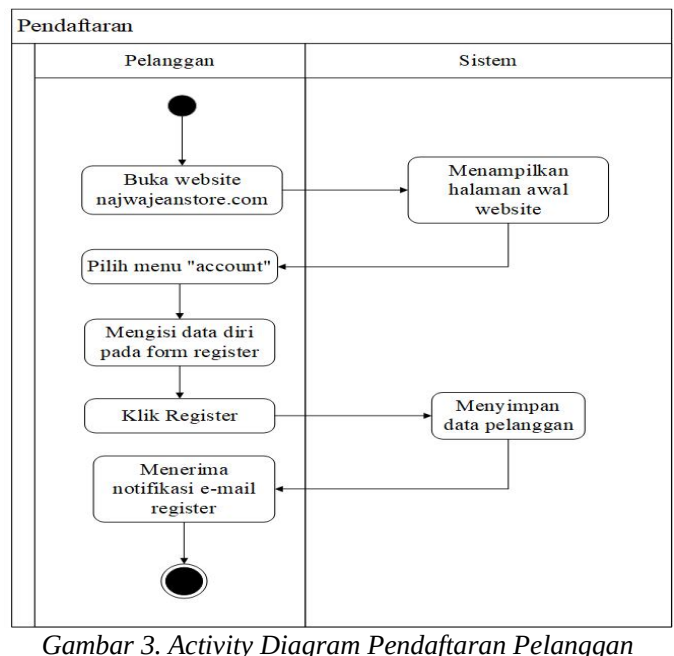

Gambar 3 merupakan proses activity diagram pendaftaran pelanggan.

\section{b. Activity Diagram Login Pelanggan}

Pelanggan yang sudah melakukan register kemudian kembali mengklik menu account kemudian mengisi form login, setelah terisi kemudian pelanggan klik tombol login.

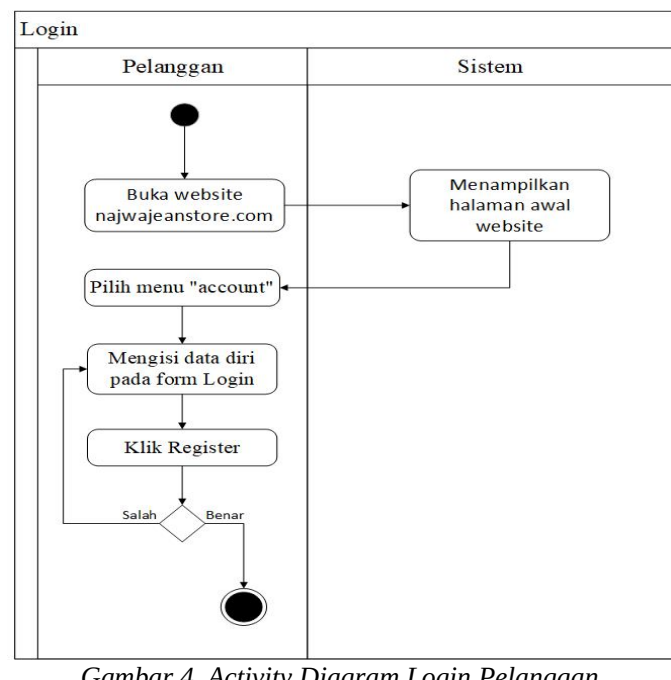

Gambar 4. Activity Diagram Login Pelanggan

Gambar 4 merupakan proses activity diagram login pelanggan. 
c. Activity Diagram Login Admin

Admin akan login backend website dengan memasukan username atau email serta password lalu klik tombol login dan akan muncul tampilan dashbord.

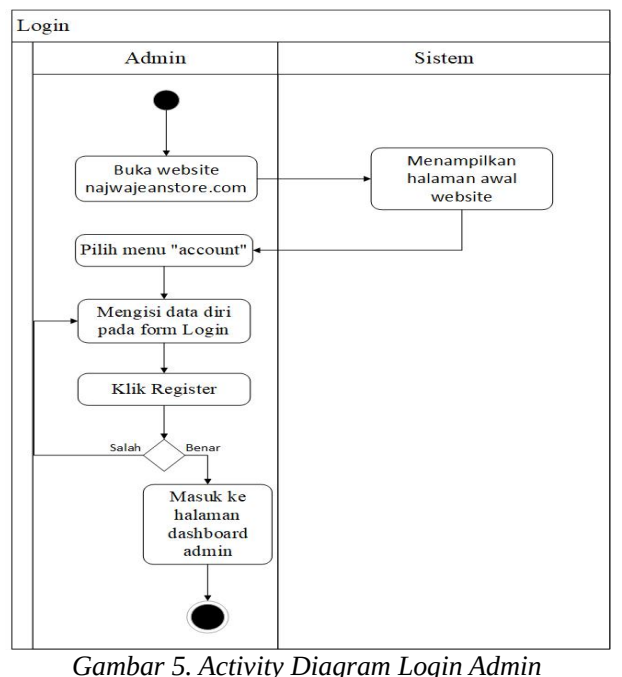

Gambar 5 merupakan proses activity diagram login admin.

\section{d. Activity Diagram entry Produk}

Proses entry produk dilakukan oleh admin dengan login terlebih dahulu, kemudian admin entry produk dan data produk dengan memasukkan harga produk, deskripsi produk, stok, foto produk, lalu memilih kategori produk kemudian klik publish dan disimpan.

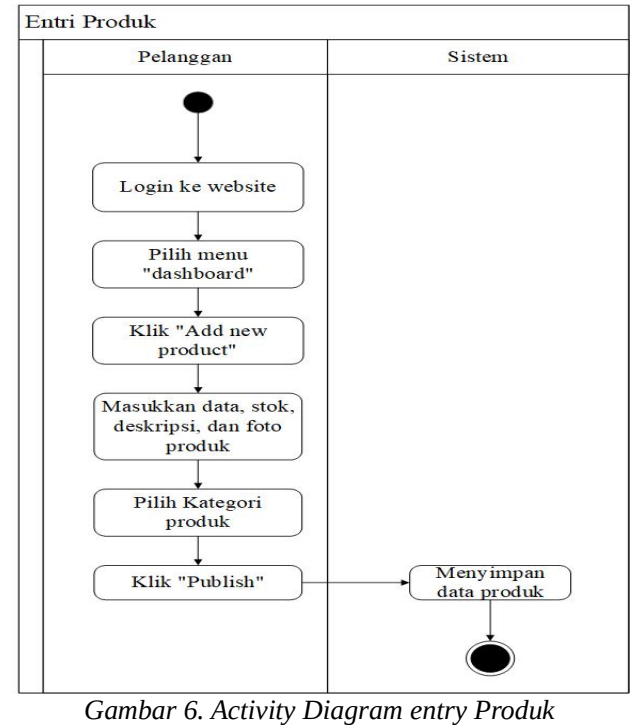

Gambar 6 merupakan proses activity diagram entry produk.

e. Activity Diagram entry kategori
Admin melakukan login terlebih dahulu setelah itu admin masuk ke halaman dashboard kemudian mengklik produk lalu klik categories lalu entry data kategori kemudian klik add new category dan kategori akan tersimpan.

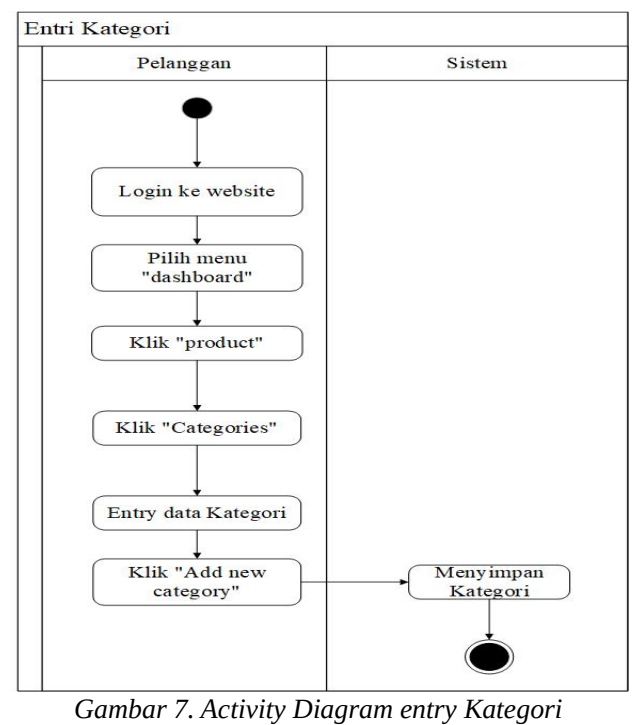

Gambar 7 merupakan proses activity diagram entry kategori.

f. Activity Diagram entry atribut

Admin login terlebih dahule ke website najwajeanstore.com lalu memilih menu dashboard kemudian klik attributes. Setelah selesai masukkan data atribut produk lalu klik add attribute dan selesai.

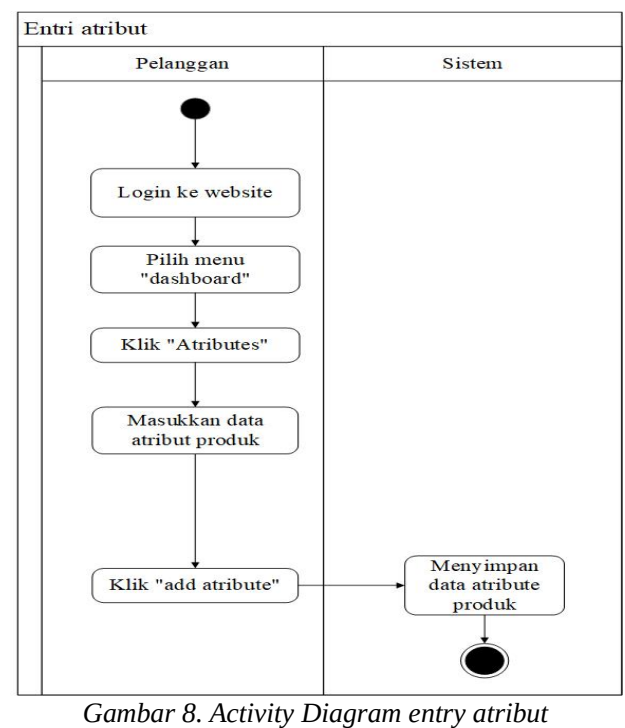

Gambar 8 merupakan proses activity diagram entry atribut.

g. Activity Diagram pemesanan 
Pelanggan yang akan memesan harus memiliki akun agar bias melakukan proses pemesanan. Pertama pelanggan harus login ke website kemudian pelanggan memilih menu jeans lalu memilih kategori yang diinginkan apakah ingin celana Panjang atau pendek. Setelah itu pilih produk yang akan dipesan, kemudian pilih tombol add to cart yang nantinya akan diarahkan ke keranjang belanja. Setelah itu masukkan jumlah barang yang diinginkan. Setelah semua proses selesai lalu klik tombol proceed to checkout kemudian isi form checkout dengan data diri pelanggan, setelah selesai pilih pengiriman yang diinginkan lalu klik tombol place order kemudian pelanggan akan mendapatkan form checkout dan pelanggan mendapatkan email invoice lalu pelanggan melakukan pembayaran sesuai email invoice yang diterima.

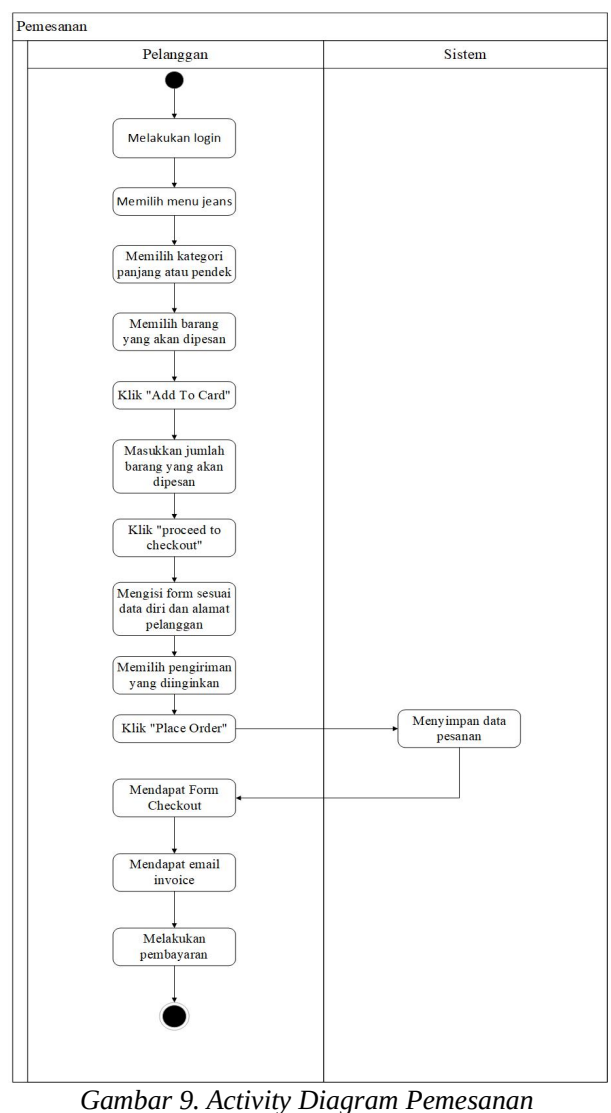

Gambar 9 merupakan proses activity diagram pemesanan.

h. Activity Diagram Konfirmasi Pembayaran

Pelanggan memilih menu payment confirmation lalu pelanggan mengisi form payment confirmation setelah selesai admin mengecek orderan dan mengubah status pesanan.

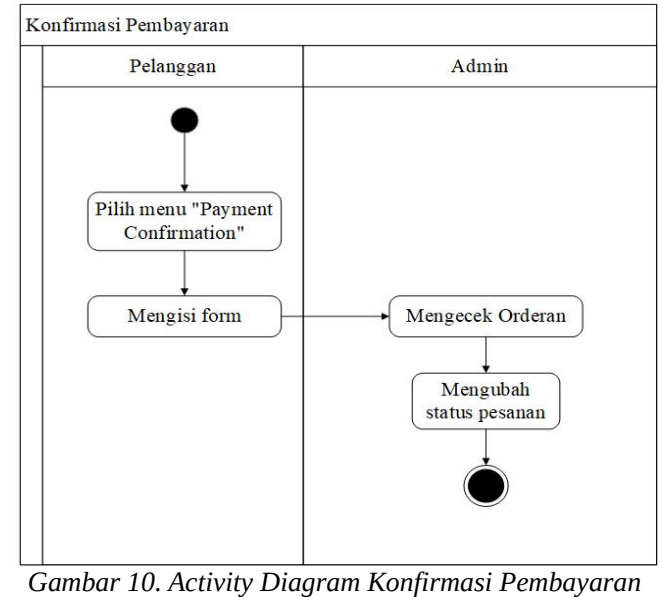

Gambar 10 merupakan proses activity diagram konfirmasi pembayaran.

i. Activity Diagram Pengiriman

Admin mengirim produk ke alamat yang diisi oleh customer. Ekspedisi menerima produk yang dikirim kemudian memberi nomor resi. Admin menginput nomor resi kemudian pelanggan menerima nomor resi dan mengecek nomor resi di menu cek resi lalu pelanggan melacak keberadaan barang sampai barang diterima.

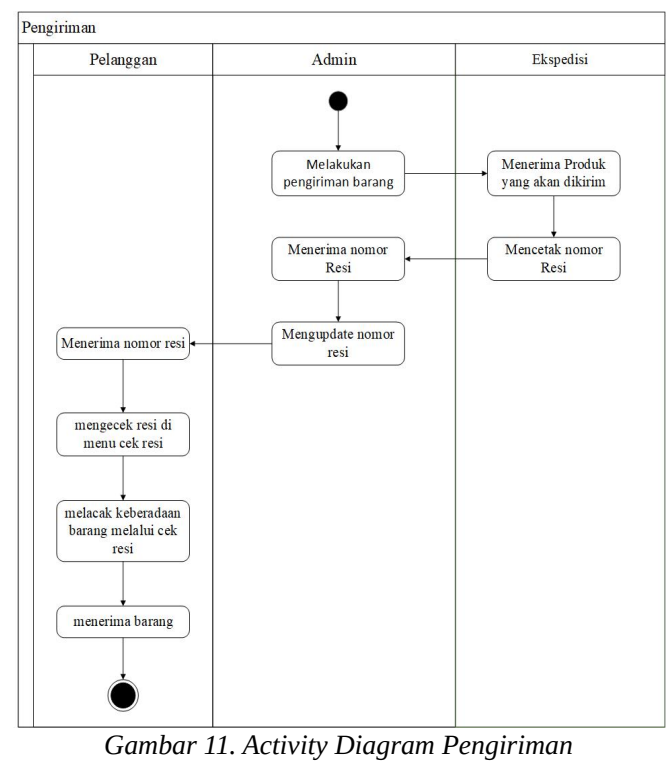

Gambar 11 merupakan proses activity diagram pengiriman.

\section{j. Activity Diagram Penerimaan}

Ketika produk sudah sampai pada pelanggan, maka pada halaman website my account klik menu Orders lalu pilih barang diterima. Maka otomatis sistem akan mengubah status pesanan dari processing menjadi completed. 


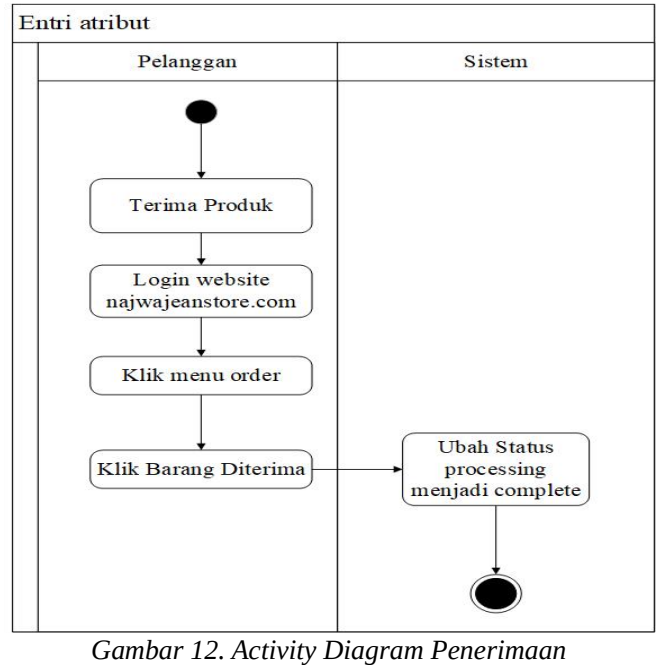

Gambar 12 merupakan proses activity diagram penerimaan

\section{k. Activity Diagram Laporan}

Admin login halaman backend website. Pada menu ini, Admin dapat memilih laporan yang ingin dicetak. Kemudian Admin dapat melihat memberikan laporan tersebut kepada owner.

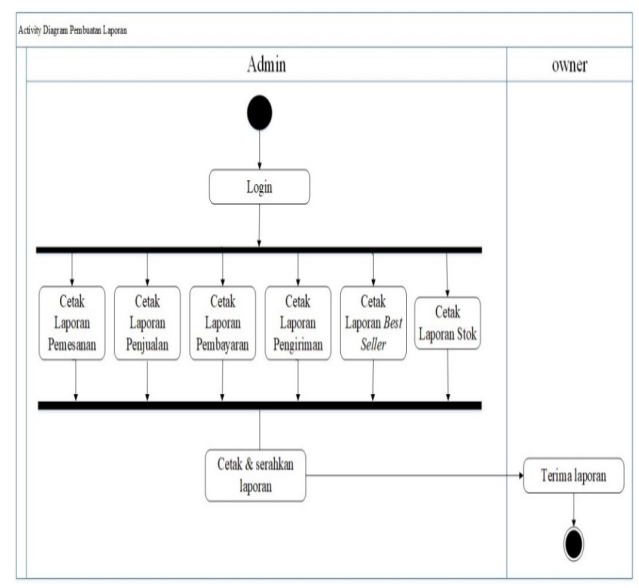

Gambar 13. Activity Diagram Laporan laporan.

Gambar 13 merupakan proses activity diagram

\subsection{Use Case Diagram}

a. Master Pelanggan

Use case master pelanggan menggambarkan pelanggan dapat register dan login.

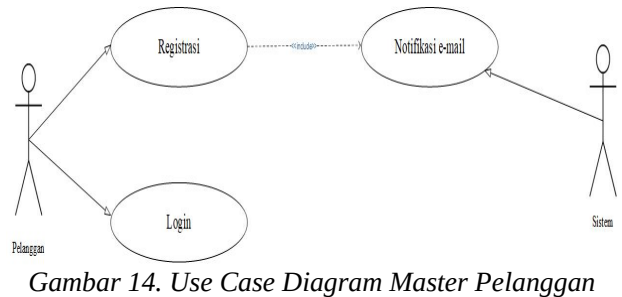

Gambar 14 merupakan Use Case Diagram master pelanggan.

b. Master Admin

Use Case Diagram Master Admin menggambarkan bahwa admin dapat mengentry kategori, produk, attribute, dan resi pada website najwa jeans.

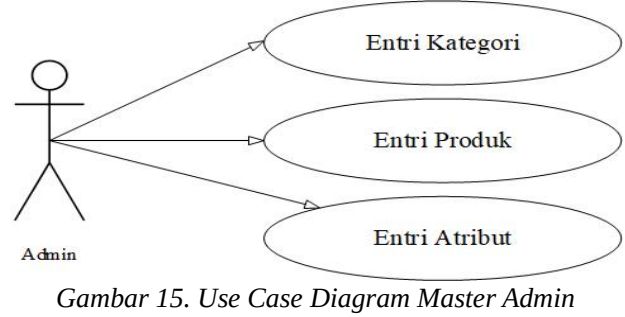

Gambar 15 merupakan Use Case Diagram Master Admin

c. Transaksi Pelanggan

Use Case Diagram transaksi pelanggan menggambarkan bahwa pelanggan dapat melakukan entri pesanan yang nantinya akan medapatkan e-mail invoice, konfirmasi pembayaran yang nantinya juga akan mendapatkan notifikasi e-mail, dan terima pesanan yang nantinya akan berubah menjadi completed.

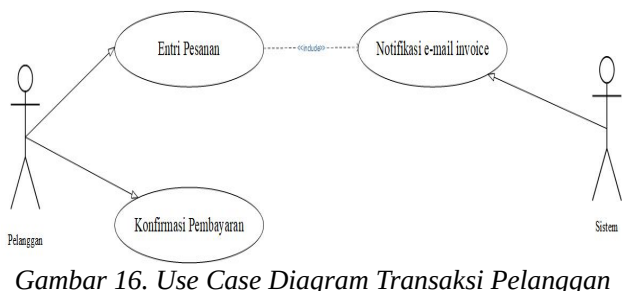

Gambar 16 merupakan use case diagram transaksi pelanggan.

d. Transaksi Admin

Use Case Diagram transaksi admin menggambarkan bahwa admin dalam transaksi dapat melakukan view pesanan, verifikasi pembayaran, konfirmasi pengiriman.

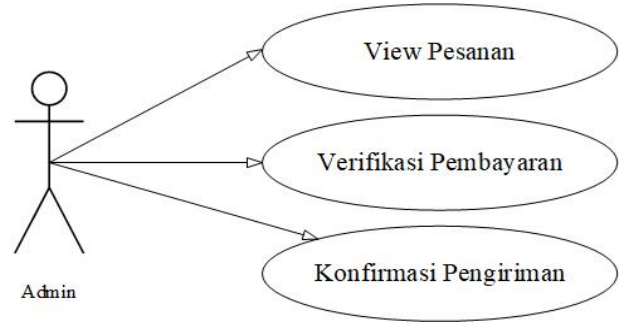

Gambar 17. Use Case Diagram Transaksi Admin

Gambar 17 merupakan use case diagram transaksi admin

e. Use Case Diagram Laporan 
Use Case Diagram Laporan berisi Cetak Laporan Pemesanan, Cetak Laporan Penjualan, Cetak Laporan Pembayaran, Cetak Laporan Pengiriman, Cetak Laporan Best Seller dan Cetak Laporan Stok.

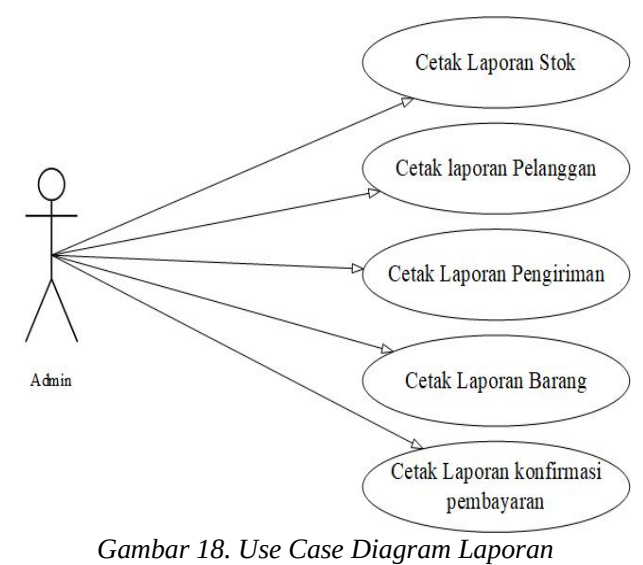

Gambar 18 merupakan use case diagram laporan.

\subsection{Class Diagram}

Class diagram berperan dalam menangkap struktur dari semua kelas yang membentuk arsitektur sistem yang dibuat.

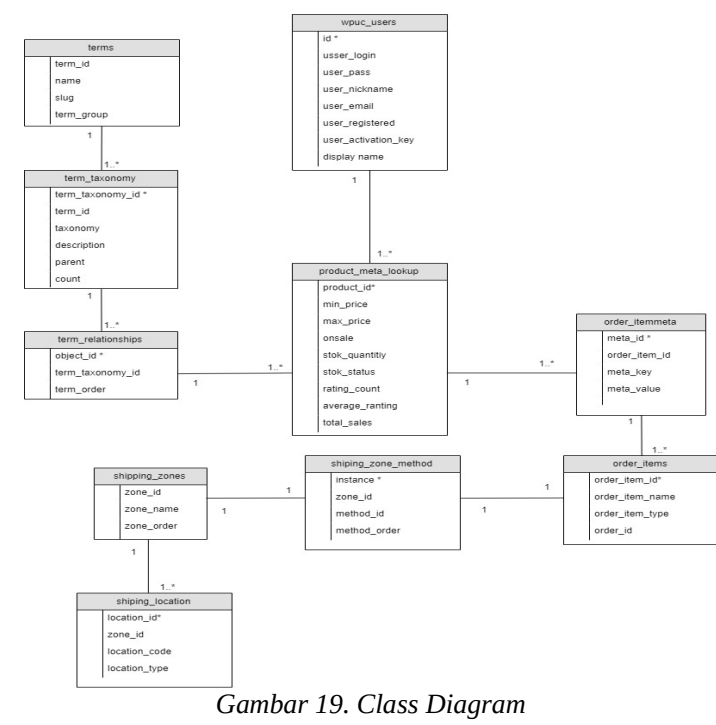

Gambar 19 merupakan class diagram pada website najwajeanstore.com.

\subsection{Rancangan Layar}

\section{a. Rancangan Layar Login}

Halaman website ini muncul ketika user mengunjungi situs najwajeanstore.com dan pelanggan memilih menu account.

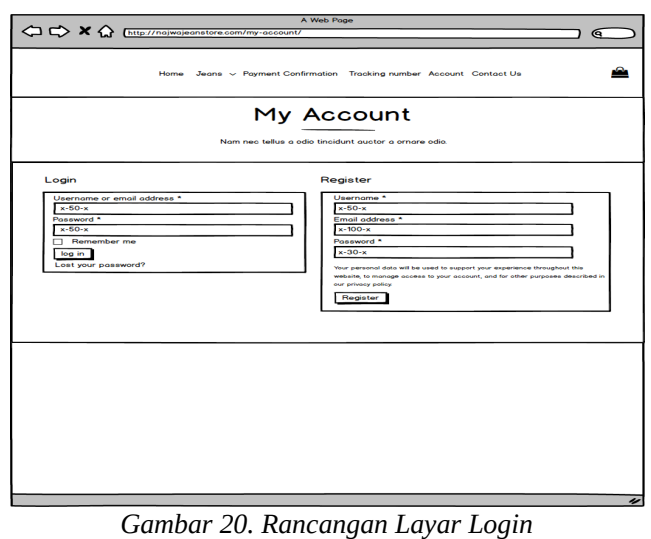

Gambar 20 merupakan rancangan layar login pada website najwajeanstore.com

\section{b. Rancangan Layar Shop}

Halaman ini muncul ketika pelanggan masuk ke halaman store najwajeanstore.com dan pelanggan bias memilih barang yang akan dibeli.

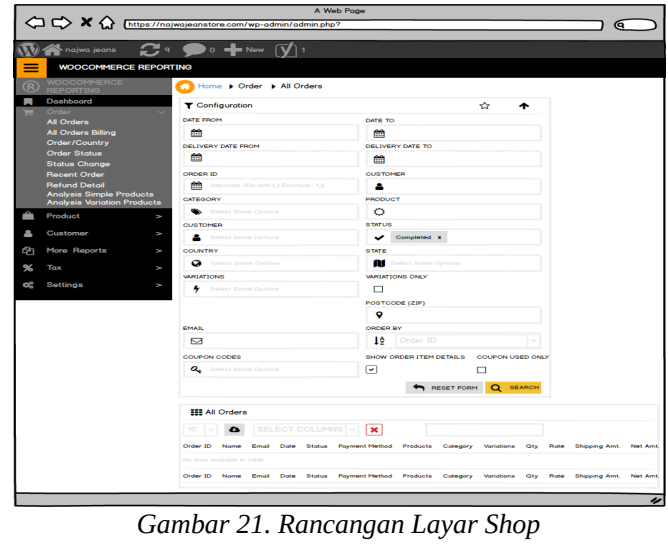

Gambar 21 merupakan rancangan layar shop pada website najwajeanstore.com

\section{c. Rancangan Layar Laporan Penjualan}

Halaman ini digunakan admin untuk melihat laporan penjualan barang pada najwajeanstore.com.

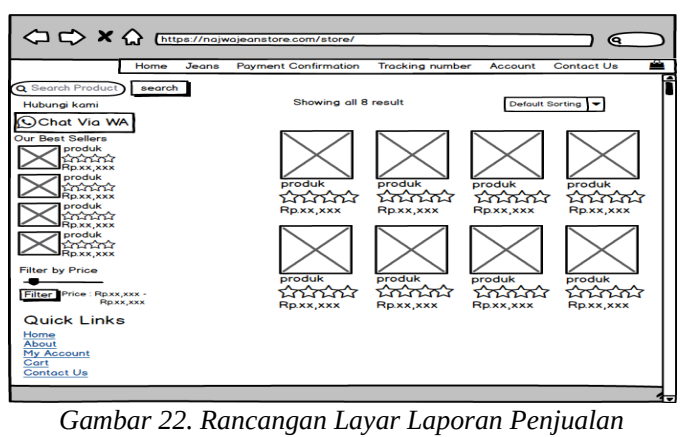

Gambar 22 merupakan rancangan layar laporan penjualan pada website najwajeanstore.com 


\subsection{Search Engine Optimization}

Optimasi website yang dibangun selanjutnya diterapkan SEO dengan membuat peta situs untuk memberikan informasi mengenai seluruh halaman dan konten yang ada didalam website najwajeanstore.com, yang dilakukan yaitu Penerapan Focus Keyphrase, Penerapan SEO title, Penerapan Meta Description, dan Menampilkan halaman pertama di pencarian.

\section{KESIMPULAN}

Dengan adanya Penerapan Metode ECommerce Untuk Meningkatkan Penjualan Barang Pada Toko Najwa Jeans ini mampu meningkatkan fitur promosi barang sehingga mempeluas jangkauan promosi kepada pelanggan, mempermudah pembuatan laporan untuk pengambilan keputusan, mempermudah pemilik toko dalam mengecek stok barang yang ada, dan dapat membuat pelanggan melakukan transaksi online tanpa harus datang langsung ke toko dan menjadi efisien.

\section{DAFTAR PUSTAKA}

[1] Hastanti, R.P., Purnama, B.E., dan Wardati, I.U., Sistem Penjualan Berbasis Web (E-Commerce) Pada Tata Distro Kabupaten Pacitan, Jurnal Bianglala, 3(2), 1-9. 2015.

[2] Manulang, D., Abdillah, L. A., \& Kurniawan. Sistem Informasi Penjualan Online (E-Commerce) Menggunakan CMS Wordpress pada Toko Soraya Shop dengan Menerapkan Metode RAD. SHaPSITI, 7-12.2017.

[3] Wulandari, aprilia siska., Sistem Informasi Penjualan Produk Berbasis Web Pada Chanel Distro Pringsewu. Jurnal TAM (Technology Acceptance Model), 4, 1-7.2015. 